\title{
The Cerebral Blood Flow Correlates of Emotional Facial Processing in Mild Alzheimer's Disease
}

\author{
Roger T. Staff ${ }^{1 *}$, Trevor S. Ahearn ${ }^{2}$, Louise H. Phillips ${ }^{3}$, Clare Scott ${ }^{3}$, Donald Mowat ${ }^{4}$, \\ Claude Wischik ${ }^{4}$, Lawrence J. Whalley, Alison D. Murray ${ }^{2}$
}

${ }^{1}$ Aberdeen Royal Infirmary, NHS-Grampian U.K.; ${ }^{2}$ Department of Radiology, University of Aberdeen, Aberdeen, U.K.; ${ }^{3}$ Department of Mental Health, University of Aberdeen, Aberdeen, U.K.; ${ }^{4}$ Department of Psychology, University of Aberdeen, Aberdeen, U.K. E-mail: r.staff@abdn.ac.uk

Received August 23 ${ }^{\text {rd }}, 2010$; revised September $13^{\text {th }}, 2010$; accepted November $20^{\text {th }}, 2010$.

\begin{abstract}
Deficits in facial emotion processing are features of mild Alzheimer's disease (AD). These impairments are often distressing for carers as well as patients. Such non-cognitive symptoms are often cited as a contributing reason for admission into institutionalised care. The ability to interpret emotional cues is crucial to healthy psychological function and relationships and impaired emotional facility may lead to antisocial behavior. Understanding the origins of the noncognitive aspects of $A D$ may lead to an improvement in the management of sufferers and ease the carer burden. In a cross-sectional study we recorded patients' facial processing abilities, (emotion and identity recognition), disease severity (ADAS-cog, Neuropsychiatic Inventory) and investigated the regional cerebral blood flow correlates of facial emotion processing deficits using ${ }^{99}{ }^{T}{ }^{m}$ HMPAO rCBF SPECT. Using statistical parametric mapping (SPM) we identified decreased blood flow in posterior frontal regions specifically associated with emotion perception deficits and independent of non-emotional facial processing abilities or/and disease severity. The posterior frontal lobe has been identified in previous studies in the absence of dementia as being important in emotion processing. The results suggest that the cognitive disease severity, in combination with the facial processing ability, do not completely explain facial emotion processing in $A D$ patients and that the posterior frontal lobe mediates such behaviour.
\end{abstract}

Keywords: Alzheimer's Disease, Emotion, SPECT, rCBF, Facial Processing, Dementia

\section{Introduction}

Impaired ability to understand the emotions of others has often been reported in fronto-temporal dementia [1], but there is also evidence that the ability to recognize and interpret emotional signals is impaired in other dementing conditions such as Alzheimer's disease (AD) [2]. These impairments are often distressing for carers and patients. Such non-cognitive symptoms are often cited as a contributing reason for admission into institutionalised care [3]. The ability to interpret emotional cues is crucial to healthy psychological function and relationships $[4,5]$ and impaired emotional facility may lead to antisocial behavior. Behavioral symptoms are common in patients with dementia and can occur throughout the disease [6]. The origin and nature of such emotional impairments in $\mathrm{AD}$ is unclear. Understanding such deficits may lead to an improvement in management and ease the burden on patients and carers.

Functional brain imaging studies in people without dementia identified the anatomies activated when presented with emotional stimuli. A meta analysis by Phan et al. [7], concluded that the medial prefrontal cortex has a general role in emotion processing, while the subcallosal cingulate and amygdala are more specifically engaged when processing sadness and fear respectively. Their far-reaching conclusions identify a specific number of candidate neuro-anatomical locations that are potentially altered by $\mathrm{AD}$ [8], and when impaired may also result in a failure in emotion processing and the emergence of behavioral symptoms.

Similar conclusions are reached after examining the effects of brain injury on emotion processing. Key areas 
identified are the amygdalae [9], orbito-frontal cortex and adjacent medial prefrontal cortex [8], and the anterior temporal cortex [10]. A more general observation is that the right hemisphere is more important in emotion processing [11]. An investigation using visual stimuli by Rosen et al. [12] of the volumetric correlates of emotion recognition suggested that regions in the right lateral and inferolateral temporal lobe are important in the recognition of emotion. Emotion processing is a broad term describing the features, mechanisms and responses triggered by emotional stimuli. Deficits in emotion processing may be specific to the type of stimulus presented [12]. Similarly, the way in which the stimulus is presented, be it visual, auditory or involving some form of recall, may influence which brain regions are selectively activated [7]. Different dementia types may also have characteristic profiles of emotion processing deficits. Shimokawa et al. [13] identified differences in the comprehension of emotion in $\mathrm{AD}$ and vascular types of dementia and Keane et al. [1] found differences between variants of fronto-temporal dementia (FTD).

Early investigations of emotion processing in dementia suggested that deficits could be explained by other neuropsychological impairments in AD [14,15]. These enquiries also found no difference between $\mathrm{AD}$ patients and controls when the emotional stimulus was auditory rather than visual. Later reports suggest that emotion processing deficits were not accounted for by cognitive impairment [1,16,17]. However, these studies mostly examined patients with FTD, where emotional deficits are central features of the disorder. Shimokawa et al. [13] found an association between the Mini Mental State Examination (MMSE) score and emotion recognition in patients with vascular dementia, but not in those with AD.

Imaging techniques allow estimates of regional cerebral blood flow (rCBF) and regional glucose uptake and reveal characteristic patterns of deficits in $\mathrm{AD}$ and other dementias. Change in such measurements often precede structural changes [18]. rCBF SPECT has revealed a number of anatomical sites associated with behavioural symptoms in AD $[3,19,20]$. Studies have also explored the correlates of emotional behaviour in dementia. Lebert et al. [21] investigated $\mathrm{AD}$ patients with $\mathrm{rCBF}$ SPECT and found greater frontal asymmetry in the exhibiting disturbed emotional behaviour. Le Ber et al. [22] in a group with FTD patterns found evidence that different behavioural presentations at onset were related to different anatomical localizations of degenerative damage. Few studies have applied metabolic imaging to emotion processing in $\mathrm{AD}$. These reports comprise substantial evidence that facial emotion processing is impaired in $\mathrm{AD}$, and prompt examination of the following questions: (1) What are the rCBF correlates of emotion perception impairment? (2) Is there evidence that these correlates are independent of the deficits in nonemotional facial processing? (3) Is there evidence that these correlates are independent of dementia severity or other behavioral symptoms?

\section{Methods}

\subsection{Patient Selection}

A retrospective review of our research and clinical database identified 20 patients who satisfied the Diagnostic and Statistical Manual of Mental Disorders (DSM-IV) criteria (American Psychiatric Association, 1994) for Probable AD and the NINCDS-ADRDA criteria for AD [23] (12 male, 8 female, aged $73 \pm 9$ years). The Local Research Ethics Committee approved the study and informed consent was received form all patients and/or carers.

\subsection{Dementia Severity}

The Alzheimer's disease assessment scale (ADAS-cog) [24] and MMSE [25] were completed before imaging. Non-cognitive symptoms comprising: delusions, hallucinations, agitation, dysphoria, anxiety, apathy, irritability, euphoria, disinhibition, aberrant motor behavior, night-time behaviour disturbances, and appetite and eating abnormalities were recorded using the using the Neuropsychiatric Inventory (NPI) [26]. These scores were not normally distributed, so the presence/absence of "significant non-cognitive psychopathology" was classified as an NPI score was equal to/greater or less than seven.

\subsection{Emotional Expression Labelling (EEL)}

Patients' abilities to identify facial emotions were tested using an emotional expression labelling test (EEL). This test consists of a standard set of 48 photos of facial expressions (Facial Expressions of Emotion: Stimuli and Tests, FEEST) [27]. The expressions depicted were fear, surprise, anger, disgust, happiness and sadness, which were displayed by four individuals. The order of the photographs was randomised, and each was presented one-by-one on a computer screen accompanied by the six emotion labels. The task was to select the emotion label that best described the facial expression. The test score is given as the percentage of faces correctly matched.

\subsection{Benton Test (BT)}

The ability to detect facial identity was tested using the Benton test of facial recognition, which is a perceptual face-matching test in which each trial entails the comparison of a target face with six faces shown below. All 
seven faces remain in view until the participant indicates which of the comparison faces appears to match the target [28]. Each patient is presented with 22 target faces. The test score is given as the percentage of faces correctly matched.

\subsection{Image Acquisition}

The patient was allowed to rest in a darkened room before injection with $500 \mathrm{MBq}$ of ${ }^{99} \mathrm{Tc}^{\mathrm{m}}$ labelled hexamethyl propylene amine oxime (HMPAO) [29]. Using a dual headed gamma camera and LEHR collimator we acquired 128 views over $360^{\circ}$ (pixel size $=3.38 \mathrm{~mm}$ ). The data were reconstructed using filtered back projection and corrected for attenuation.

\subsection{Statistical Parametric Mapping (SPM)}

Images were spatially normalised to the SPM SPECT template, re-sampled at $4 \times 4 \times 4 \mathrm{~mm}$ voxels and then smoothed with an 8mm Gaussian kernel. This was done using the SPM2 package (University College, Queens Square London). The images were then intensity normalised (to the mean cerebellum uptake).

\subsection{Results}

Table 1 summarises the study data. NPI scores greater than seven were seen in seven patients. Comparisons between these patients and those with lower scores revealed a significant difference on the EEL task $(\mathrm{F}=14.3$, $\mathrm{p}=0.001$ ) while the group difference was close to significance on the BT task $(\mathrm{F}=3.8, \mathrm{p}=0.06)$. Table 1 also shows Pearson correlation coefficients between the measures. The results show significant associations between emotion labelling and identity recognition and between identity recognition and dementia severity. Age

Table 1. Means (standard deviation)of acquired data and Pearson correlations; ADAS-cog-Alzheimer's Disease Assessment Scale (cognition), MMSE-Mini Mental State Examination, EEL-emotion expression labelling, BT Benton Test. * Correlation is significant at the $p<0.05$ level (2tailed), ** Correlation is significant at the $\mathrm{p}<0.01$ level (2tailed).

\begin{tabular}{|c|c|c|c|c|c|}
\hline & \multirow{2}{*}{$\begin{array}{c}\text { Mean } \\
\text { (SD) }\end{array}$} & \multicolumn{4}{|c|}{ Pearson correlations } \\
\hline & & $\begin{array}{c}\text { ADAS- } \\
\text { cog }\end{array}$ & MMSE & EEL & $\mathrm{BT}$ \\
\hline $\begin{array}{l}\text { Age } \\
\text { (years) }\end{array}$ & $\begin{array}{l}72.5 \\
(9.0)\end{array}$ & -0.025 & 0.143 & 0.199 & 0.375 \\
\hline $\begin{array}{l}\text { ADAS- } \\
\text { Cog }\end{array}$ & $\begin{array}{l}20.1 \\
(9.4)\end{array}$ & - & $-0.618^{* *}$ & -0.147 & $-0.457 *$ \\
\hline MMSE & $\begin{array}{l}22.3 \\
(4.0)\end{array}$ & & - & 0.368 & 0.286 \\
\hline EEL & $\begin{array}{c}56.2 \\
(13.6)\end{array}$ & & & - & $0.662 * *$ \\
\hline $\mathrm{BT}$ & $\begin{array}{c}71.8 \\
(71.8)\end{array}$ & & & & - \\
\hline
\end{tabular}

was not significantly associated with any measures. As expected, the MMSE and ADAS-cog score were associated.

The initial SPM analysis shows significant areas (uncorrected $\mathrm{p}<0.005$ ) of correlation between rCBF and the EEL and BT scores (Figure 1) (cluster volumes > 200 voxels), showing that lower performance on these tests is associated with less rCBF. A detailed description of the locations of significant associations is shown in Table 2. Figure 1 also identifies the significant areas of rCBF difference between those with and without significant psychopathology as indicated by NPI scores. No significant correlations were found between ADAS-cog scores and rCBF. The EEL analysis shows three large clusters in the left posterior frontal lobe, the right parietal lobe and in the right posterior frontal lobe, all of which contain voxels of corrected significance $(\mathrm{p}<0.05)$. The BT analysis pin-points four large significant clusters in the parietal lobes bilaterally and in the right and left posterior frontal lobes. Each of these has significant corrected $(\mathrm{p}<0.05)$ cluster level significance and contains voxels that have a corrected significance $(\mathrm{p}<0.05)$. The NPI comparison shows a single region in the left parietal lobe that has only cluster level significance $(\mathrm{p}<0.05)$.

Repeating the SPM analysis for EEL with BT as a nuisance variable, the significant EEL associations in the bilateral posterior frontal lobes were maintained ( $\mathrm{p}<$ 0.05) (Table 2). When EEL is analysed using ADAS$\operatorname{cog}$ as the nuisance variable, a large, significant, convoluted cluster that extended from the left posterior frontal lobe to the right parietal lobe was detected. This cluster had only one significant voxel level location in the left posterior frontal lobe (Table 2). The analysis also showed a region in the right posterior frontal lobe showed a trend but was not significant $(p=0.053)$. When EEL was analysed with NPI status as the nuisance variable, among three previously identified EEL clusters, only the left posterior frontal cluster was maintained. Testing for association between EEL and rCBF using all of the potential nuisance variables together in the model, the significant association between EEL and ICBF was maintained in the left posterior frontal lobe (Table 2, Figure 2). As with the previous comparisons, a close to voxel level significant location was indicated in a similar region, on the contra-lateral side (24 $232, \mathrm{p}=0.083$ ).

\section{Discussion}

The main finding was that in AD patients there is a significant association between rCBF and facial emotion and non-emotion processing abilities. After adjustment for facial non-emotion processing abilities and disease severity, there remains a significant association between facial emotion processing and $\mathrm{rCBF}$ in the posterior 


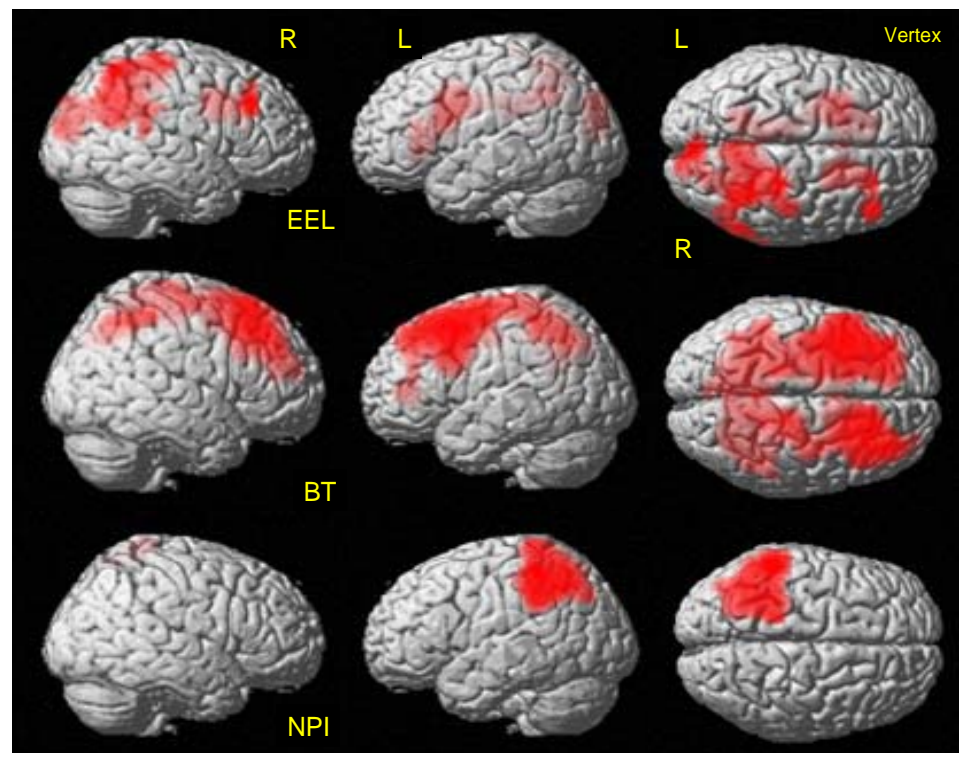

Figure 1. The areas of significant uncorrected $(p<0.005)$ correlation between $r C B F$ and emotion expression labelling (EEL), identity recognition on the Benton Test (BT), and Neuropsychiatry inventory (NPI).
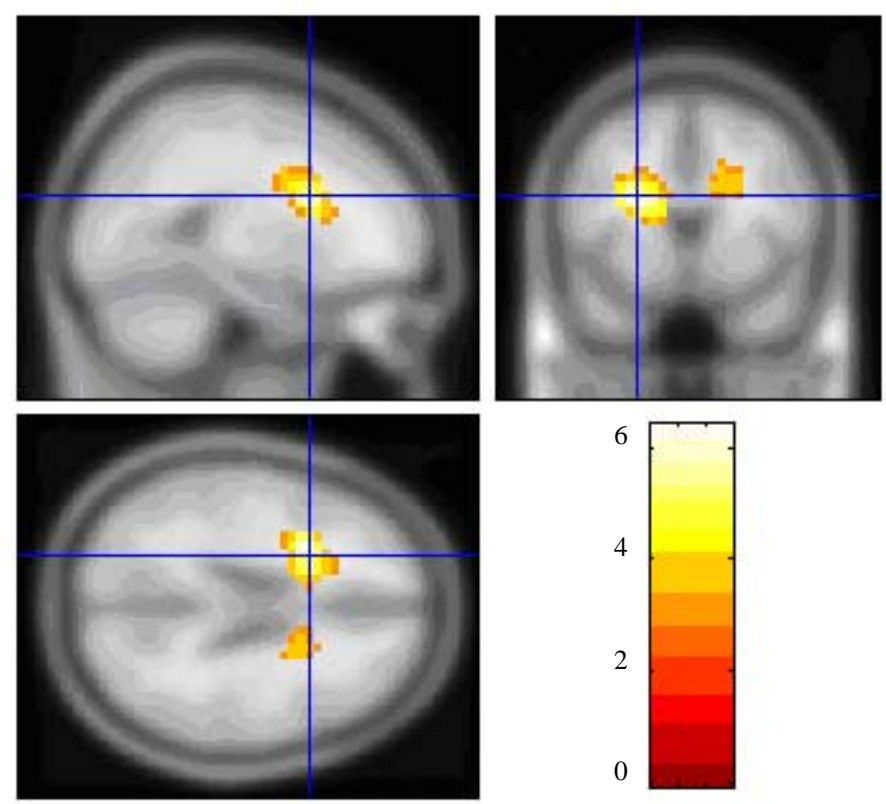

Figure 2. Regions of significant association between EEL and rCBF, (nuisance variables: ADAS—Cog, BT and NPI status). The region is super-imposed on the SPM2 $\mathrm{t} 1$ template. The region was created using a $\mathrm{p}<\mathbf{0 . 0 0 5}$ threshold. The colour scale is representative of the $t$ value.

frontal lobes. These data are consistent with the findings of Hargrave et al. [30] and Allender and Kaszniak [31], who in non-imaging studies suggested that an impairment in facial emotion processing in AD cannot be completely explained by deficits in more general aspects of facial processing. In addition, we show that the cognitive disease severity, in combination with the facial processing ability, do not completely explain the association between $\mathrm{rCBF}$ in the posterior frontal lobe and facial emotion processing by $\mathrm{AD}$ patients. It is not possible to determine from these data if a deficit in this region is representative of disease severity not captured by ADAScog or NPI.

The spatial resolution of rCBF SPECT is limited and the degree of atrophy may vary substantially in this sample, so it is difficult to identify with absolute confidence 
Table 2. The SPM results showing the locations and the uncorrected and corrected voxel and cluster level significances (ADAS-cog-Alzheimer's Disease Assessment Scale (cognition), MMSE-Mini Mental State Examination, EEL-emotion expression labelling, BT Benton Test. * Correlation is significant at the $\mathbf{p}<0.05$ level (2-tailed), R-Right, L-Left).

\begin{tabular}{|c|c|c|c|c|c|c|c|}
\hline & $\begin{array}{l}\text { Cluster Location } \\
\text { Description }\end{array}$ & $\begin{array}{c}\text { Peak Co- } \\
\text { ordinates } \\
\text { x y z }\end{array}$ & $\begin{array}{c}\text { Voxel p } \\
\text { Un-corrected }\end{array}$ & $\mathrm{t}$ & $\begin{array}{l}\text { Voxel FDR } \\
\text { Corrected p }\end{array}$ & $\begin{array}{l}\text { Cluster Size } \\
\text { (voxels) }\end{array}$ & $\begin{array}{l}\text { Corrected } \\
\text { Cluster p }\end{array}$ \\
\hline \multirow{3}{*}{ EEL } & $\begin{array}{l}\text { L Posterior } \\
\text { Frontal Lobe }\end{array}$ & -28824 & $<0.001$ & 6.34 & 0.031 & 654 & $<0.001$ \\
\hline & $\begin{array}{l}\text { R Parietal } \\
\text { Lobe }\end{array}$ & $16-4835$ & $<0.001$ & 4.91 & 0.039 & & \\
\hline & $\begin{array}{l}\text { R Posterior } \\
\text { Frontal Lobe }\end{array}$ & 24436 & $<0.001$ & 4.86 & 0.039 & 224 & 0.026 \\
\hline \multirow{4}{*}{ BT } & $\begin{array}{l}\text { L Posterior } \\
\text { Frontal lobe }\end{array}$ & -40844 & $<0.001$ & 5.75 & 0.016 & 431 & 0.002 \\
\hline & $\begin{array}{l}\text { L Parietal } \\
\text { Lobe }\end{array}$ & $-12-5636$ & $<0.001$ & 5.29 & 0.016 & 217 & 0.034 \\
\hline & $\begin{array}{l}\text { R Parietal } \\
\text { Lobe }\end{array}$ & $16-3256$ & $<0.001$ & 4.15 & 0.019 & & \\
\hline & $\begin{array}{l}\text { R Posterior } \\
\text { Frontal Lobe }\end{array}$ & 363640 & $<0.001$ & 5.13 & 0.016 & 485 & $<0.001$ \\
\hline NPI & L Parietal Lobe & $-64-4044$ & $<0.001$ & 5.00 & 0.171 & 537 & $<0.001$ \\
\hline \multirow{2}{*}{$\begin{array}{l}\text { EEL (nuisance } \\
\text { variable BT) }\end{array}$} & $\begin{array}{l}\text { L Posterior } \\
\text { Frontal Lobe }\end{array}$ & -28820 & $<0.001$ & 6.11 & 0.024 & 143 & 0.023 \\
\hline & $\begin{array}{l}\text { R Posterior } \\
\text { Frontal Lobe }\end{array}$ & 28436 & $<0.001$ & 5.89 & 0.024 & 67 & 0.214 \\
\hline $\begin{array}{l}\text { EEL (nuisance } \\
\text { variable ADAS-cog) }\end{array}$ & $\begin{array}{l}\text { L Posterior Frontal } \\
\text { R Parietal Lobe }\end{array}$ & -28824 & $<0.001$ & 6.25 & 0.042 & 569 & $<0.001$ \\
\hline \multirow{3}{*}{$\begin{array}{l}\text { EEL (nuisance } \\
\text { variable NPI status) }\end{array}$} & $\begin{array}{l}\text { L Posterior } \\
\text { Frontal Lobe }\end{array}$ & -28824 & $<0.001$ & 6.22 & 0.046 & 298 & 0.011 \\
\hline & $\begin{array}{l}\text { R Posterior } \\
\text { Frontal Lobe }\end{array}$ & 28436 & $<0.001$ & 4.86 & 0.047 & 171 & 0.069 \\
\hline & R Parietal Lobe & $16-4840$ & $<0.001$ & 4.97 & 0.047 & 245 & 0.023 \\
\hline $\begin{array}{l}\text { EEL (nuisance } \\
\text { variable NPI status, } \\
\text { ADAS-cog, BT) }\end{array}$ & $\begin{array}{l}\text { L Posterior } \\
\text { Frontal Lobe }\end{array}$ & -28820 & $<0.001$ & 6.41 & 0.040 & 189 & 0.039 \\
\hline
\end{tabular}

those anatomical locations upon which this significant cluster of voxels is superimposed. However, the posterior frontal location identified in this study includes the superior longitudinal fasciculus, the lateral aspects of the corpus callosum, parts of Brodmann area 24 (anterior cingulate) and Brodmann 32 (medial frontal gyrus).

The EEL task requires emotion processing abilities that are not required in the BT tasks. One interpretation is that the region in the posterior frontal lobe identified, is concerned with the semantic labelling of and/or the reaction to emotions depicted by facial cues. The medial pre-frontal cortex which includes Brodmann 24 and 32 has been previously identified as important in the processing of affect-related meanings that are common to many forms of emotion processing [32,33]. In addition, Brodmann 24 and 32 were shown to be active in the self regulation of emotions in children [34]. The significant associations in the current study appear to be independent of other impairments, measured using ADAS-cog and NPI. This conflicts with another report [14], which suggested that deficits in emotion processing in $\mathrm{AD}$ were a result of cognitive and/or neuropsychological impair- ment. The findings reported in the present study are, however, consistent with those of Keane et al. [1] and Rosen et al. [16] who identified regions in the ventromedial frontal cortex associated with the impaired recognition of emotions in dementia.

The MMSE and ADAS-cog scores place our patients in the range of mild dementia severity. Data derived from Mukaetova-Landinska et al. [35] suggest that mild dementia approximates to Braak stage 3 or 4 of AD neuropathology [36]. AD subjects at Braak stages 3 and 4 have no frontal pathology. Similarly, volumetric studies have found little atrophy in the frontal lobes in patients with mild AD $[37,38]$. PET studies have also found little evidence to suggest that the frontal lobes have extensive neuropathology early in the course of disease [39]. This would suggest that there is little AD pathology at this location in the current population. The association between emotion recognition and frontal blood flow may therefore reflect pre-existing individual differences in the functioning of brain regions involved in emotion recognition. Individual differences in the processing of emotions have been shown to be present in the context 
of measuring emotional intelligence [40]. In the face of the cognitive and neural burden brought on by $\mathrm{AD}$, those individuals with greatest frontal lobe blood flow may be most able to maintain emotion processing ability as compared to those with less flow. This indicates that rCBF at this location might be considered as a proxy of 'emotional reserve'. In this case we describe emotional reserve as the ability to maintain emotion processing in the face of burden brought about by AD. The concept of reserve has been commonly applied to cognition and describes the apparent protection from the onset of clinical dementia and/or cognitive decline in old age [41].

Although pathological, volumetric and metabolic imaging studies have indicated little frontal lobe involvement in early $\mathrm{AD}$, our finding could be explained by coexisting cerebrovascular disease in the frontal lobes. Previously we have shown [42] that vascular burden is commonplace in normal old people and is most evident in the frontal white matter. It may well be that these behavioural findings are a consequence of vascular pathologies, co-existing with $\mathrm{AD}$ pathology in the posterior brain.

Although our patients were well characterised, the number is small and an independent replication would strengthen these conclusions. The image resolution of an rCBF SPECT study is also a weakness and limits our ability to anatomically locate the significant findings. An alternative would be to use rCBF or FDG PET, with superior spatial resolution. An fMRI study may also illuminate the situation further; however, implementation of lengthy functional imaging paradigms in this patient group is difficult. The inclusion of a healthy elderly control group would also be informative as to the origins of our findings and potentially answer the questions: (1) are these differences brought about by AD progression; (2) do they reflect pre-existing individual differences; or (3) are they the consequence of additional vascular burden? Increasing the sample size would also enable us to investigate the processing of individual emotions. This seems important because there is evidence that $\mathrm{AD}$ impairs recognition of specific emotions while leaving others intact [43].

\section{Acknowledgements}

The Authors would like to thank TauRx Therapeutics Ltd, Aberdeen, UK and The Alzheimer's Research Trust for their support.

\section{REFERENCES}

[1] J. Keane, A. J. Calder, J. R. Hodges and A. W. Young. "Face and Emotion Processing in Frontal Variant Frontotemporal Dementia.” Neuropsychologia, Vol. 40, No. 2, 2002, pp. 655-65. doi:10.1016/S0028-3932(01)00156-7
[2] L. Brosgole, J. Kurucz, T. J. Plahovinsak, C. Spr-otte and Y. A. Haveliwala. "Facial-Affect and Postural-Affect Recognition in Senile Elderly Persons.” International Journal of Neurosciences, Vol. 22, No. 1-2, 1983, pp.3745. doi:10.3109/00207459308987383

[3] S. E. Starkstein, S. Vazquez, G. Petracca, L. Sabe, R. Migliorelli, A. Teson and R. Leiguarda. "A Spect Study of Delusions in Alzheimers-Disease.” Neurology, Vol. 44, No. 11, 1994, pp. 2055-2059.

[4] B. M. Depaulo. "Nonverbal Behavior and Self-Presentation,” PsycholBull, Vol. 111, 1992, pp. 203-243.

[5] J. S. Carton, E. A. Kessler and C. L. Pape. "Nonverbal Decoding Skills and Relationship Well-Being in Adults.” Journal of Nonverbal Behavior, Vol. 23, 1999, pp. 91100. doi:10.1023/A:1021339410262

[6] T. Hope, J. Keene, C. G. Fairburn, R. Jacoby and R. McShane. "Natural History of Behavioural Changes and Psychiatric Symptoms in Alzheimer's Disease: A Longitudinal Study,” British Journal of Psychiatry, Vol. 174, 1999, pp. 39-44. doi:10.1192/bjp.174.1.39

[7] K. L. Phan, T. Wager, S. F. Taylor and I. Liberzon. "Functional Neuroanatomy of Emotion: A Meta-Analysis of Emotion Activation Studies in PET and fMRI," Neuroimage, Vol. 16, No.2, 2002, pp. 331-48. doi:10.1006/nimg.2002.1087

[8] D. Horinek, A. Varjassyova and J. Hort. "Magnetic Resonance Analysis of Amygdalar Volume in Alzheimer's Disease," Current Opinion in Psychiatry, Vol. 20, 2007, pp. 273-7.

[9] R. Adolphs, H. Damasio, D. Tranel and A. R. Damasio. "Cortical Systems for the Recognition of Emotion in Facial Expressions,” Journal of Neuroscience, Vol. 16, 1996, pp. 7678-87.

[10] A. K. Anderson, D. D. Spencer, R. K. Fulbright and E. A. Phelps. "Contribution of the Anteromedial Temporal Lobes to the Evaluation of Facial Emotion," Neuropsychology, Vol. 14, 2000, pp. 526-36.

doi:10.1037/0894-4105.14.4.526

[11] J. C. Borod, B. A. Cicero, L. K. Obler, J. Welkowitz, H. M. Erhan, C. Santschi, I. S. Grunwald, R. M. Agosti and J. R. Whalen, "Right Hemisphere Emotional Perception: Evidence across Multiple Channels," Neuropsychology, Vol. 12, 1998, pp. 446-58.

doi:10.1037/0894-4105.12.3.446

[12] H. J. Rosen, M. R. Wilson, G. F. Schauer, S. Allison, M. L. Gorno-Tempini, C. Pace-Savitsky, J. H. Kramer, R. W. Levenson, M. Weiner and B. L. Miller. "Neuroanatomical Correlates of Impaired Recognition of Emotion in Dementia,” Neuropsychologia, Vol. 44, 2006, pp. 365373. doi:10.1016/j.neuropsychologia.2005.06.012

[13] A. Shimokawa, N. Yatomi, S. Anamizu, I. Ashikari, M. Kohno, Y. Maki, S. Torii, H. Isono, Y. Sugai, N. Koyama and Y. Matsuno, "Comprehension of Emotions: Comparison between Alzheimer Type and Vascular Type Dementias,” Dement Geriatr Cogn Disord , Vol. 11, 2000, pp. 268-74. doi:10.1159/000017249 
[14] M. S. Albert, C. Cohen and E. Koff. "Perception of Affect in Patients with Dementia of the Alzheimer Type." Archives of Neurology, Vol. 48, 1991, pp. 791-795.

[15] E. Koff, D. Zaitchik, J. Montepare and M. S. Albert, "Emotion Processing in the Visual and Auditory Domains by Patients with Alzheimer's Disease,” Journal of the International Neuropsychological Society , Vol. 5, 1999, pp. 32-40. doi:10.1017/S1355617799511053

[16] H. J. Rosen, R. J. Perry, J. Murphy, J. H. Kramer, P. Mychack, N. Schuff, M. Weiner, R. W. Levenson and B. L. Miller, "Emotion Comprehension in the Temporal Variant of Frontotemporal Dementia,” Brain, Vol. 125, 2002, pp. 2286-2295. doi:10.1093/brain/awf225

[17] H. J. Rosen, K. Pace-Savitsky, R. J. Perry, J. H. Kramer, B. L. Miller and R. W. Levenson, "Recognition of Emotion in the Frontal and Temporal Variants of Frontotemporal Dementia," Dement Geriatr Cogn Disord, Vol. 17,2004, pp. 277-81. doi:10.1159/000077154

[18] D. Wyper, E. Teasdale, J. Patterson, D. Montaldi, D. Brown, R. Hunter, D. Graham and J. Mcculloch. "Abnormalities in Rcbf and Computed-Tomography in Patients with Alzheimers-Disease and in Controls,” British Journal of Radiology, Vol. 66, 1993, pp. 23-27. doi:10.1259/0007-1285-66-781-23

[19] R. T. Staff, M. F. Shanks, L. Macintosh, S. J. Pestell, H. G. Gemmell and A. Venneri, "Delusions in Alzheimer's Disease: SPET Evidence of Right Hemispheric Dysfunction.” Cortex, Vol. 35,1999, pp. 549-60.

\section{doi:10.1016/S0010-9452(08)70818-9}

[20] P. H. Robert, G. Darcourt, M. P. Koulibaly, S. Clairet, M. Benoit, R. Garcia, O. Dechaux and J. Darcourt. "Lack of Initiative and Interest in Alzheimer's Disease: A Single Photon Emission Computed Tomography Study,” European Journal of Neurology, Vol. 13, 2006, pp. 729-35. doi:10.1111/j.1468-1331.2006.01088.x

[21] F. Lebert, F. Pasquier, M. Steinling and H. Petit. "Affective-Disorders Related to Spect Patterns in AlzheimersDisease: A Study of Emotionalism." International Journal of Geriatric Psychiatry, Vol. 9, 1994, pp. 327-329.

doi:10.1002/gps.930090410

[22] I. Le Ber, E. Guedj, A. Gabelle, P. Verpillat, M. Volteau, C. Thomas-Anterion, M. Decousus, D. Hannequin, P. Vera, L. Lacomblez, A. Camuzat, M. Didic, M. Puel, J. Lotterie, V. Golfier, A. Bernard, M. Vercelletto, C. Magne, F. Sellal, I. Namer, B. Michel, J. Pasquier, F. Salachas, J. Bochet, A. Brice, M. Habert, B. Dubois and French Res Network FTD FTD MND, "Demographic, Neurological and Behavioural Characteristics and Brain Perfusion SPECT in Frontal Variant of Frontotemporal Dementia," Brain, Vol. 129, 2006, pp. 3051-3065. doi:10.1093/brain/awl288

[23] D. Blacker, M. S. Albert, S. S. Bassett, R. C. P. Go, L. E. Harrell and M. F. Folstein, "Reliability and Validity of Nincds-Adrda Criteria for Alzheimers-Disease - the National-Institute-Of-Mental-Health Genetic Initiative,” Arch Neurology, Vol. 51, 1994, pp. 1198-1204.

[24] P. M. Doraiswamy, F. Bieber, L. Kaiser, K. R. Krishnan,
J. ReuningScherer and B. Gulanski, “The Alzheimer's Disease Assessment Scale: Patterns and Predictors of Baseline Cognitive Performance in Multicenter Alzheimer's disease trials," Neurology, Vol. 48, 1997, pp. 1511-7.

[25] R. M. Crum, J. C. Anthony, S. S. Bassett and M. F. Folstein, "Population-Based Norms for the Mini-MentalState-Examination by Age and Educational-Level," Journal of the American Medical Association, Vol. 269, 1993, pp. 2386-91. doi:10.1001/jama.269.18.2386

[26] J. L. Cummings, “The Neuropsychiatric Inventory: Assessing Psychopathology in Dementia Patients.” Neurology, Vol. 48, 1997, pp. S10-16.

[27] A.W. Young, C. A. J. Perret, R. Sprengelmeyer, P. Ekman, "Facial Expressions of Emotion: Stimuli and Tests," (FEEST), Harcourt Assessment, 2002.

[28] A. L. Benton, H. de Ken and N. R. Varney, "Contributions to Neuropsychological Assessment: A Clinical Manual," 1994.

[29] H. G. Gemmell, P. F. Sharp, F. W. Smith, J. A. O. Besson, K. P. Ebmeier, J. Davidson, N. T. S. Evans, D. Roeda, R. Newton and J. R. Mallard, "Cerebral BloodFlow Measured by Spect as a Diagnostic-Tool in the Study of Dementia,” Psychiatry Research, Vol. 29, 1989, pp. 327-329. doi:10.1016/0165-1781(89)90079-6

[30] R. Hargrave, R. J. Maddock and V. Stone, “Impaired Recognition of Facial Expressions of Emotion in Alzheimer's Disease,” Journal of Neuropsychiatry Clinical Neurosciences, Vol. 14, 2002, pp. 64-71.

doi:10.1176/appi.neuropsych.14.1.64

[31] J. Allender and A. W. Kaszniak. "Processing of Emotional Cues in Patients with Dementia of the Alzheimers Type.” International Journal of Neurosciences, Vol. 46, 1989, pp. 147-155. doi:10.3109/00207458908986252.

[32] A. Heinzel, F. Bermpohl, R. Niese, A. Pfennig, A. Pascual-Leone, G. Schlaug and G. Northoff, "How Do We Modulate Our Emotions? Parametric FMRI Reveals Cortical Midline Structures As Regions Specifically Involved in the Processing of Emotional Valences," Cognitive Brain Research, Vol. 25, 2005, pp. 348-358.

[33] J. D. Teasdale, R. J. Howard, S. G. Cox, Y. Ha, M. J. Brammer, S. C. R. Williams and S. A. Checkley, "Functional MRI Study of the Cognitive Generation of Affect." American Journal of Psychiatry, Vol. 156, 1999, pp. 209-215.

[34] J. Levesque, Y. Joanette, B. Mensour, G. Beaudoin, J. M. Leroux, P. Bourgouin and M. Beauregard, "Neural Basis of Emotional Self-Regulation in Childhood," Neuroscience, Vol. 129, 2004, pp. 361-369.

\section{doi:10.1016/j.neuroscience.2004.07.032}

[35] E. B. Mukaetova-Ladinska, F. Garcia-Siera, J. Hurt, H. J. Gertz, J. H. Xuereb, R. Hills, C. Brayne, F. A. Huppert, E. S. Paykel, M. McGee, R. Jakes, W. G. Honer, C. R. Harrington and C. M. Wischik, "Staging of cytoskeletal and beta-amyloid changes in human isocortex reveals biphasic synaptic protein response during progression of Alzheimer's disease,” American Journal of Pathology, 
Vol. 157, 2000, pp. 623-636.

doi:10.1016/S0002-9440(10)64573-7

[36] H. Braak and E. Braak, "Neuropathological Staging of Alzheimer-Related Changes,” Acta Neuropathol ,Vol. 82, 1991, pp. 239-259. doi:10.1007/BF00308809

[37] J. C. Baron, G. Chetelat, B. Desgranges, G. Perch-ey, B. Landeau, V. de la Sayette and F. Eustache, "In Vivo Mapping of Gray Matter Loss with Voxel-Based Morphometry in Mild Alzheimer's Disease.” Neuroimage, Vol. 14, 2001, pp. 298-309. doi:10.1006/nimg.2001.0848

[38] R. I. Scahill, J. M. Schott, J. M. Stevens, M. N. Rossor and N. C. Fox, "Mapping the evolution of regional atrophy in Alzheimer's disease: Unbiased Analysis of FluidRegistered Serial MRI," Proceedings of National Academic Sciences in USA, Vol. 99, 2002, pp. 4703-4707. doi:10.1073/pnas.052587399

[39] J. V. Haxby, C. L. Grady, E. Koss, B. Horwitz, M. Schapiro, R. P. Friedland and S. I. Rapoport, "Heterogeneous Anterior-Posterior Metabolic Patterns in Dementia of the Alzheimer Type,” Neurology, Vol. 38, 1998,. pp.
1853-1863.

[40] J. D. Mayer, D. R. Caruso and P. Salovey, "Emotional Intelligence Meets Traditional Standards for an Intelligence," Intelligence, Vol. 27, 1999, pp. 267-298. doi:10.1016/S0160-2896(99)00016-1

[41] R. T. Staff, A. D. Murray, I. J. Deary and L. J. Whalley, "What Provides Cerebral Reserve?" Brain, Vol. 127, 2004, pp. 1191-1199. doi:10.1093/brain/awh144

[42] A. D. Murray, R. T. Staff, S. D. Shenkin, I. J. Deary, O. M. Starr and L. J. Whalley, "Brain white Matter Hyperintensities: Relative Importance of Vascular Risk Factors in Nondemented Elderly People,” Radiology, Vol. 237, 2005, pp. 251-257. doi:10.1148/radiol.2371041496

[43] J. D. Henry, T. Ruffman, S. McDonald, M. P. O'Leary, L. H. Phillips, H. Brodaty and P. G. Rendell, "Recognition of disgust is Selectively Preserved in Alzheimer's Disease,” Neuropsychologia, Vol. 46, 2008, pp. 1363-1370. doi:10.1016/j.neuropsychologia.2007.12.012 